\title{
Parto natural: a atuação do enfermeiro diante da assistência humanizada.
}

\author{
Natural childbirth: the work of nurses in the face of \\ humanized care.
}

\section{El parto natural: el trabajo de las enfermeras en la cara de la atención humanizada.}

\author{
Sinara Santos Pereira \\ Izabela Cristina Martins dos Santos Oliveira ${ }^{2}$ \\ Josiane Bom da Silva Santos ${ }^{3}$ \\ Maria Cristina de Melo Pessanha Carvalho ${ }^{4}$
}

\begin{abstract}
RESUMO: A pesquisa teve como objeto de estudo a atuação do enfermeiro no parto natural na perspectiva da humanização e tem como objetivos identificar as ações cuidadoras que o enfermeiro implementa no parto normal, verificar os fatores que interferem na humanização da assistência de enfermagem no parto natural e ampliar a visão dos enfermeiros em relação às reações percebidas pelas gestantes após o recebimento da assistência humanizada. A pesquisa justifica- se pela incidência de mortalidade materna e perinatal ocorridas durante o parto cesáreo. Trata-se de uma pesquisa descritiva com abordagem qualitativa que teve como sujeitos um quantitativo de 05 enfermeiros obstetras. O cenário da pesquisa foi uma maternidade de pequeno porte da Região Sul Fluminense do Médio Paraíba. A coleta de dados realizou-se a partir de um roteiro de entrevista individual através de questionário com perguntas abertas. Para a verificação dos dados utilizou-se a análise temática de conteúdo, agrupando-os em um sistema de categorias. Observou-se que as enfermeiras entrevistadas detêm o conhecimento prático, teórico e científico sobre a humanização do parto e realizam a assistência de acordo com seus conhecimentos, porém ainda existem fatores que as impedem na manutenção dessas ações.

Palavras-chaves: parto natural, humanização; enfermeiras obstétricas.
\end{abstract}

\footnotetext{
1 Mestre em Enfermagem pela Universidade Estadual do Rio de Janeiro. Coordenadora da Pós-Graduação Oncologia em Enfermagem e Relatora do Comitê e Ética em Pesquisa do Centro Universitário de Barra Mansa. Brasil. Enfermeira da Secretaria Municipal de saúde do Município de Resende. E-mail: sinaraconsultoria@hotmail.com 2 Centro Universitário de Barra Mansa. Brasil. Secretaria de Saúde de Angra dos Reis. E-mail: izarcmartins@hotmail.com

3 Graduação em Enfermagem pelo Centro Universitário de Barra Mansa. Brasil. Enfermeira da Secretaria de Saúde de Angra dos Reis. E-mail: josiibom@yahoo.com.br

4 Doutora em Enfermagem pela Escola de Enfermagem Anna Nery - Universidade Federal do Rio de Janeiro. Professora visitante do Programa de Pós-Graduação do Centro Universitário de Barra Mansa. Brasil. Enfermeira do Ministério da Saúde. E-mail: mcrismelo4@hotmail.com
} 
ABSTRACT: The object of study of this research was the work of nurses in natural childbirth from the perspective of humanization. Its objectives were to describe the humanized care provided by nurses during natural childbirth, identify factors that interfere with the humanization of nursing care in natural birth and raise the view of nurses regarding the reactions perceived by pregnant women after receiving humanized care. This study is justified by the incidence of maternal and perinatal mortality occurred during cesarean delivery. It is a descriptive research with qualitative approach that has as participants an amount of five obstetrician nurses. The research scenario was a small-sized maternity hospital at the South Fluminense of Middle Paraiba region. Data collection was carried out from an individual interview script, through a questionnaire with open questions. For data analysis researchers used the thematic content analysis, by grouping them into a system of categories. It was observed that the interviewed nurses have practical, theoretical and scientific knowledge about the humanization of birth and carry out assistance according to their knowledge, but there are still factors that hinder the maintenance of these actions.

RESUMEN: La investigación tuvo como objeto de estudio el trabajo de las enfermeras en el parto natural desde la perspectiva de humanización. Sus objetivos fueron identificar acciones de cuidado que la enfermera implementa en el parto normal, identificar los factores que afectan a la humanización de la atención de enfermería en el parto natural y elevar la visión de las enfermeras con respecto a las reacciones percibidas por las mujeres embarazadas después de la recepción de la asistencia humanizada. El estudio se justifica por la incidencia de la mortalidad materna y perinatal se produjo durante el parto por cesárea. Se trata de una investigación descriptiva con enfoque cualitativo que tuvo como tuvo como participantes 05 parteras. El sitio de la investigación fue una maternidad pequeña de la región sur del Paraíba Fluminense Medio. La recolección de datos ocurrió a partir de un guión de entrevista individual a través de un cuestionario con preguntas abiertas. Para el análisis de datos se utilizó el análisis temático de contenido, agrupándolos en un sistema de categorías. Se observó que las enfermeras entrevistadas tiene el conocimiento práctico, teórico y científico de la humanización del parto y realizar asistencia de acuerdo con sus conocimientos, pero todavía hay factores que impiden el en la manutención de estas acciones.

\section{INTRODUÇÃO}

Em tempos remotos, a assistência obstétrica pertencia somente às parteiras, que com experiência, realizavam os partos em residências e tinham também o reconhecimento da sociedade. A partir do século XX, esta prática foi transferida para o ambiente hospitalar, trazendo a medicalização e favorecendo à submissão da mulher com a perda de privacidade e autonomia ${ }^{1}$

O parto é um processo natural e fisiológico que desde os primórdios era realizado de maneira instintiva pela mulher e auxiliado por pessoas que tinham certo conhecimento sobre o nascimento, porém após a institucionalização desse processo, o parto tornou-se mecanizado e tecnicista protagonizado geralmente pelo profissional médico que entende o parto como doença e que realiza 
procedimentos intervencionistas dispensáveis para tratá-lo. Assim, o profissional deixa de lado o contexto psicossocial que envolve esse momento, desumanizando a mulher e retirando todo o seu poder e vontade sobre esse procedimento.

O parto humanizado, por outro lado, é entendido como prática de cuidado ao parto e ao nascimento, garantindo uma qualidade de assistência segura que valoriza a escolha do ato de dar à luz de forma natural privativa e familiar. O conceito de atenção humanizada é amplo e envolve um conjunto de conhecimentos, práticas e atitudes que visam à promoção do parto e do nascimento saudável e à prevenção da morbimortalidade materna e perinatal ${ }^{2}$. Faz- se necessário uma relação de confiança, que foque às necessidades e anseios da parturiente, além de permitir uma concepção segura.

O período gestacional até o parto deve atender às necessidades da mulher e do bebê, evitando intervenções desnecessárias e preservando sua privacidade e autonomia. Sendo assim, é importante a avaliação do enfermeiro para acompanhar o desenvolvimento do feto e zelar pelo bem estar da mãe. Esse acompanhamento envolve o diagnóstico de eventuais enfermidades e as orientações corretas a serem seguidas ${ }^{3}$.

Para o bom desenvolvimento do trabalho de parto é necessário o bem-estar físico e emocional da mulher, o que reduz os riscos e complicações. Para tanto, o respeito ao direito da mulher à privacidade, à segurança, à assistência humana e de qualidade, aliado ao apoio familiar durante a parturição, transformam o nascimento em um momento único e especial, além de reduzirem os riscos de morbidade e mortalidade.

As práticas humanizadoras do nascimento constituem um processo em que o profissional deve respeitar a fisiologia da concepção do bebê, não intervindo desnecessariamente, reconhecendo os aspectos sociais e culturais do parto e nascimento, oferecendo suporte emocional à mulher e sua família ${ }^{4}$.

No entanto, em consequência do avanço da tecnologia, o parto cesáreo, procedimento realizado para resolver situações obstétricas de risco, passou a ser utilizado de forma abusiva, com a justificativa errônea de ser mais seguro em relação ao parto normal. Vale destacar que o parto cesáreo é definido como a extração do feto através de uma incisão na parede abdominal (laparotomia) e na parede uterina (histerotomia). Em geral, a cesariana é realizada quando o trabalho de parto está contra indicado ou quando não é provável que o parto vaginal seja realizado com segurança

Diante dessa visão distorcida, é importante haver esforços para desestimular tais práticas inseguras as quais colocam a mulher em risco e não garante o seu bem-estar. A Organização Mundial de Saúde (OMS) argumenta que o parto humanizado tem início no pré-natal com o aconselhamento e orientações, respeitando a individualidade da parturiente, seus desejos e, durante o trabalho de parto, dar liberdade de escolha quanto à posição mais apropriada e agradável para parir6 . 
Para garantir a segurança e o bem-estar da mulher durante o momento do parto normal é indispensável uma atenção adequada e de qualidade, por isso, a equipe de saúde deve estar pronta para acolher a gestante e seus familiares, estando bem preparada e fundamentada cientificamente para realização de procedimentos e de eventuais intercorrências, além de uma visão focada na individualidade de cada parturiente, criando vínculo e transmitindo-lhe confiança e tranquilidade.

Vale destacar que a motivação desse trabalho está relacionada ao crescente número de parto cesariano desnecessário contribuindo para a falta de humanização na assistência ao parto. As mulheres são erroneamente influenciadas pelos mitos sobre dor exacerbada durante o parto natural, medo de mudanças com o corpo, comodidade e sobre a segurança de seu filho.

Dessa forma, este estudo justifica-se na incidência de mortalidade materna e perinatal ocorridas durante o parto cesáreo, sendo o parto natural uma alternativa para preveni-la, tendo por contribuição o fundamento teórico para auxiliar o enfermeiro no campo obstétrico de forma humanística quando se trata do parto natural.

Esse estudo traz como investigação a atuação do enfermeiro no parto natural na perspectiva da humanização, definindo como objetivos identificar as ações cuidadoras que o enfermeiro implementa no parto normal, verificar os fatores que interferem na humanização da assistência de enfermagem no parto natural e ampliar a visão dos enfermeiros em relação às reações percebidas pelas gestantes após o recebimento da assistência humanizada.

\section{METODOLOGIA}

Trata-se de um estudo descritivo com abordagem qualitativa, tendo como finalidade expor os cuidados humanizados prestados pelo enfermeiro durante o parto natural. O cenário de estudo foi uma unidade de saúde situada em um município do Médio Paraíba, no Estado do Rio de Janeiro, que presta assistência ao Parto Humanizado. Os sujeitos da pesquisa foram cinco enfermeiros responsáveis pela assistência de enfermagem ao parto natural. Teve como critérios de inclusão enfermeiros formados com pelo menos dois anos de experiência, especialistas em Enfermagem Obstétrica, que prestam assistência ao parto natural em uma maternidade de pequeno porte na Região Sul Fluminense do Médio Paraíba e foram excluídos do estudo enfermeiros que não atuavam na área obstetra.

A coleta de dados realizou-se no período de julho a setembro do ano 2013 a partir de um roteiro de entrevista individual através de questionário com perguntas abertas na sala da supervisão de Enfermagem da referida maternidade e com privacidade. Os dados oriundos das entrevistas foram gravados e, após cada entrevista, transcritos na íntegra.

Para a análise do material coletado utilizou-se a análise temática de conteúdo, segundo Minayo, $2008^{7}$, compreendendo pré-análise com leituras flutuantes e exaustivas, seguidas da organização 
do material e da sistematização de ideias. Explorou-se o material com um sistema de categorização dos dados, utilizando expressões ou palavras significativas em unidades de registros e dados com interpretação dos significados dos conteúdos temáticos ${ }^{7}$. Sendo assim, o material verbal coletado formou uma concepção do enfermeiro no parto humanizado, desdobrando-se em sete categorias que indicaram a problemática do estudo: conversa terapêutica/orientação, presença do profissional de saúde, apoio emocional, presença do acompanhante, falta de aceitação da parturiente, falta de comprometimento/envolvimento da equipe, avaliação positiva/agradecimento/sorriso no rosto.

No que se refere aos aspectos éticos da pesquisa atendeu-se aos princípios da resolução 466/2012 sendo o projeto aprovado pelo Comitê de Ética do Centro Universitário de Barra Mansa, sob o protocolo número 131934. Assim, cada participante após o aceite, assinou o Termo de Consentimento Livre e esclarecido.

\section{RESULTADOS E DISCUSSÃO}

Os resultados da análise geraram sete categorias aludindo ao que os participantes do estudo indicaram em suas falas acerca do enfermeiro e do parto humanizado. Foi possível estabelecer as categorias que serão mencionadas abaixo.

\section{Categoria 1 - Conversa terapêutica/ orientação}

Dentre as ações cuidadoras implementadas durante o parto natural, essa categoria ressalta o emprego do termo "humanizar", vinculado à assistência ao parto e ao nascimento, além da importância das informações à parturiente. Tem como finalidade melhorar o entendimento da gestante, como também as condições do atendimento à mulher, à família e ao recém-nascido mediante a reivindicação de ações que visam à autonomia, à liberdade de escolha, à equidade, o resgate da atenção obstétrica integrada, qualificada e humanizada que é incentivado pelas informações conforme declarações abaixo.

\footnotetext{
“Acho importante orientar e esclarecer as dúvidas que a mulher solicitar" (E 04)

"Conversa terapêutica, informações sobre trabalho de parto devem sempre existir" (E 05)

“é imprescindível a orientação e informação sobre os meios para facilitar o parto" (E 01)
}

Percebe-se que ao informar à parturiente sobre os diversos procedimentos aos quais será submetida, oferecer um ambiente acolhedor e confortável e esclarecer suas dúvidas são ações simples e que requerem a boa vontade do profissional de saúde. O momento do parto é extremamente importante na vida de uma mulher, momento de grande tensão emocional, que afeta profundamente as mulheres, os bebês, as famílias. É essencial durante a realização da assistência ao parto 
o fornecimento de informações às mulheres e seus familiares. Conforme foi possível observar nas entrevistas, os profissionais de enfermagem fazem este ambiente acolhedor propiciando que a parturiente seja protagonista do parto ${ }^{8}$.

É fundamental fornecer informações às mulheres e aos seus familiares sempre que necessário. $\mathrm{Na}$ admissão, deve-se respeitar a privacidade da mulher e a escolha do seu acompanhante. Durante o trabalho de parto, líquidos devem ser oferecidos, além de um suporte emocional, oferecendo informações sobre os procedimentos realizados e encorajar a posição não deitada, deve-se também dar liberdade de posição e movimento à parturiente. $O$ controle da dor deve ser feito por meios não invasivos e não farmacológicos, como técnicas de relaxamento, massagens, entre outros ${ }^{5}$.

A indicação do tipo de parto para cada mãe é instituído respeitando alguns critérios que levam em consideração o bem estar da parturiente e seu filho. Neste momento é estabelecida a avaliação de risco, que define a melhor conduta a ser tomada durante a gestação e trabalho de parto. O parto normal é a maneira mais segura e saudável de ter filhos e, por isso, deve ser estimulado e realizado através de uma assistência humanizada, segura e de qualidade. A cesariana, só deve ser realizada quando for realmente necessária para proteger a gestante e o bebê. Sendo assim, a gestante tem o direito de ser informada sobre os motivos que a impedem de optar pelo parto normal.

\section{Categoria 2 - Presença do profissional de saúde}

Os profissionais de saúde são coadjuvantes desta experiência, mas desempenham importante papel, pois têm a oportunidade de colocar seu conhecimento a serviço do bem-estar da mulher e do bebê, reconhecendo os momentos críticos em que suas intervenções são necessárias para assegurar a saúde de ambos ${ }^{9}$. Podem minimizar a dor, ficar ao lado, dar conforto, esclarecer, orientar, enfim, ajudar a parir e a nascer.

“A presença do enfermeiro nesta hora é muito importante, a orientação sobre técnicas não invasivas para alívio da dor, presença do profissional para diminuição da ansiedade e aumento da segurança." (E. 05)

“Cuidar está muito além de prática profissional e procedimentos, significa estar junto a esta mulher'(E 03)

"Presença ativa transmitindo segurança, tratamento com respeito e compreensão e apoio familiar" (E 01$)$

O processo de humanização do parto e nascimento promove o envolvimento efetivo da parturiente como sujeito ativo capaz de escolhas, contribuindo para que ela tenha consciência dos seus direitos, da sua autonomia. O profissional que vislumbra uma atuação humanista deve respeitar e 
entender que os direitos, as necessidades e limites do ser humano são condição indispensável para uma assistência humanizada e de qualidade ${ }^{10}$.

Para a realização do parto natural, a puérpera deve ser acompanhada por um profissional de saúde capaz, enfermeiro ou médico, pois esse é um período crítico, além disso, a presença de um pediatra na hora do parto é indicada e prevista em lei. Os profissionais de saúde devem acolher e apoiar a gestante no momento de sua chegada, criando um relacionamento de confiança. Sua admissão precisa ser em ambiente com privacidade e onde ela se sinta segura ${ }^{11}$. Desta maneira, as enfermeiras que realizam a assistência ao parto humanizado, estabelecem com cada mulher um vínculo e percebem suas necessidades e capacidade de lidar com o processo do nascimento, dando à parturiente a segurança necessária para que este processo transcorra da forma mais natural possível, garantindo o bem estar da puérpera e do bebê com a sua presença.

\footnotetext{
"O parto deve ser colocado à mulher como uma protagonista deste evento e não apenas no domínio profissional, isso dá mais confiança à mulher” (ent. 3)
}

"Humanizar é individualizar a assistência, ou seja, atender à mulher de forma única e individual "(ent. 4)

Vale destacar, que na realização do parto humanizado, é essencial que cuidados não farmacológicos de alívio da dor sejam explorados; a equipe de enfermagem tem um papel fundamental na realização desses cuidados, proporcionando à parturiente alívio da dor através de medidas simples como liberdade de adotar posturas e posições variadas, exercícios que facilitam o trabalho de parto, deambulação, respiração ritmada e ofegante, banhos de chuveiro e de imersão, toque e massagem, dando à mulher a oportunidade de ter uma boa vivência deste momento especial que é a chegada do filho ${ }^{12}$.

“É importante cuidados como os exercícios que ajudam no trabalho de parto.” (ent. 01)

“ O estímulo à movimentação corporal, prática de exercícios respiratórios, exercícios na bola ajudam no alívio da dor" (ent. 02)

\section{Categoria 3-apoio Emocional}

Muitas vezes as mulheres sentem-se inseguras, incapacitadas e tem dificuldade nas tomadas de decisões sobre o tipo de parto e as técnicas a serem utilizadas durante o processo de parturição por não conhecerem as questões técnicas levantadas pelos profissionais da área da obstetrícia. Neste momento a enfermeira que possui o conhecimento técnico-científico tem como papel principal permanecer ao lado da mulher dando-lhe apoio e segurança, além de oferecer opções com técnicas 
para seu conforto, percebendo suas características culturais, incentivando seu poder de decisão em todo o trabalho de parto.

\footnotetext{
"É entender que a mulher possui suas vontades e desejos, mas também receios, medo. Procurar estar junto dela para o que ele precisar" (E 02)

"Além da presença do enfermeiro, do apoio emocional no parto humanizado, você dá a gestante o direito de escolha, seja os métodos de alívio da dor, a escolha do acompanhante, a posição durante o parto"(E 05)
}

Ao prestar assistência humanizada à mulher que vivencia o ciclo gravídico puerperal, os profissionais devem desenvolver habilidades relacionadas ao contato com essa mulher, favorecendo sua adequação emocional à gravidez e ao parto. Podem também ajudá-la a superar os medos, as ansiedades e as tensões. No modelo humanizado de atendimento, a parturiente e seu acompanhante devem ser recebidos pela equipe com empatia considerando sempre suas opiniões, preferências e necessidades ${ }^{13}$.

Acredita-se, que a mulher que vai parir necessita de uma assistência de enfermagem condizente com suas necessidades biopsicossociais, desde sua admissão na sala de parto até sua alta hospitalar. $\mathrm{O}$ apoio emocional deve ser extensivo ao domicílio, para uma adaptação ao novo papel materno, que geralmente é um momento em que surgem dúvidas, dificuldades e insegurança no seu desempenho ${ }^{3}$.

Observou-se nos discursos que as enfermeiras entendem o sentido da palavra humanização no parto, e agem de acordo com seu significa, dando apoio emocional e tentando empoderar as parturientes em todo o processo de parturição. Pode-se observar que a assistência prestada pelas enfermeiras tem uma conceituação contrária à cultura tecnocrata empregada nas instituições hospitalares atuais. Impera-se o cuidado humano e holístico, dando assim o poder pleno para as escolhas das ações sobre seu trabalho de parto permitindo que a mulher seja a protagonista desse processo, apoiando sempre suas necessidades individuais de modo seguro.

\section{Categoria 4 - Presença do acompanhante}

Segundo o Ministério da Saúde, a gestante tem o direito a ter um acompanhante no período de pré-parto e parto. A permanência de outra pessoa junto à mulher no parto e pós-parto proporciona tranquilidade e segurança para a puérpera, além de reduzir o tempo do trabalho de parto.

A presença do acompanhante proporciona bem-estar físico e emocional à mulher e favorece uma boa evolução no ciclo gravídico-puerperal. O acompanhante passa segurança durante todo 
o processo parturitivo, o que pode diminuir as complicações na gestação, parto e puerpério, a utilização de analgesia, ocitocina, os partos cesáreos e o tempo de hospitalização do binômio, mãe e filho ${ }^{4}$.

“Com a presença do acompanhante elas ficam mais calmas" (E 02)

“Eu envolvo o acompanhante no apoio.” (E 04)

"Acho que sempre tem que ter a presença do acompanhante." (E 05)

O acompanhante pode constituir mais do que simples presença se for permitida a sua participação durante o processo do parto. Nessa condição ele deixa de ser considerado mero representante fiscalizador da assistência obstétrica para assumir o status na rede social de provedor do suporte a parturiente ${ }^{10}$. Para as enfermeiras, a presença do acompanhante é fundamental para a puérpera, inclusive sua ajuda nesse momento, reduz os níveis de dor durante o trabalho de parto e parto. Sendo assim, é muito importante a presença do acompanhante para oferecer apoio no processo do nascimento.

A presença do acompanhante como benéfica no processo de trabalho de parto foi vista como um diferencial no modelo de parto humanizado, capaz de proporcionar à parturiente inúmeros benefícios durante todo o processo, permitindo que a mulher visualizasse a parturição de forma mais segura, protegida e com experiência da diminuição na sensação dolorosa ${ }^{9}$.

O enfermeiro pode possibilitar a parturiente um parto menos doloroso através de uma assistência humanizada com a utilização de algumas técnicas como respiração para o controle das contrações uterinas, de maneira atenta e pausada, proporcionando conforto à mulher em trabalho de parto e relaxamento muscular facilitando a dilatação e diminuindo a sensação dolorosa ${ }^{11}$.

É importante sensibilizar a parturiente e seu acompanhante quanto ao poder do corpo feminino e que ela é capaz de parir sozinha; a mulher deve ser encorajada e incentivada a cada progresso que fizer, tanto pelo acompanhante como pelo profissional: isto a deixa mais segura e empoderada ${ }^{14}$.

\section{Categoria 5 - Falta de aceitação da parturiente}

A partir desta categoria, foram extraídos relatos em que foi possível verificar a interferência na humanização da assistência ao parto normal dificultando a implementação das ações. As mulheres atualmente tendem a preferir a realização do parto cesariano. Os motivos como falta de conhecimento sobre os tipos de parto, medo de sentir dor no momento da parturição, preservação perianal, medo de intercorrências no trabalho de parto e falta de informação sobre as técnicas humanizadas de parto no pré-natal que levam as parturientes a escolherem essa opção. 
Conciliando com esses fatores a falta de tempo para aguardar todo processo do parto, maior pagamento por partos cesarianos e a insegurança na resolução de adversidade em partos com distócias são alguns dos motivos que levam o profissional médico a indicarem o parto cesariano, criando na sociedade, uma cultura de mais segurança quanto ao parto cirúrgico e a não aceitação do parto natural ${ }^{1}$.

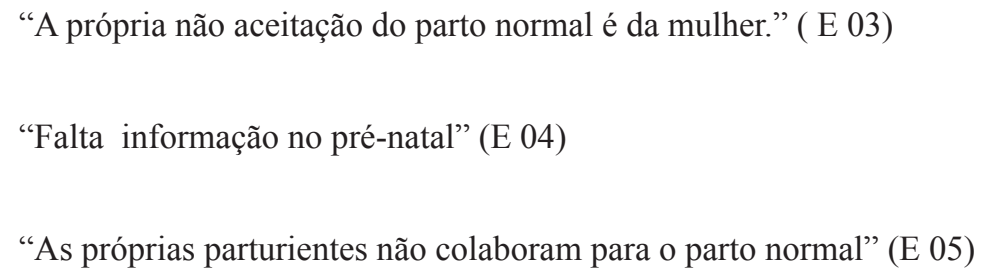

Percebeu-se nas entrevistas que uma das dificuldades da implementação das ações humanizadas é a falta de cooperação das parturientes. Só conseguiremos a contribuição dessas mulheres em seus próprios partos se as conscientizarmos da importância de sua ajuda desde o pré-natal até o momento da parturição e mostrarmos como a realização correta de técnicas humanizadas, auxiliaria e aliviaria desconfortos trazidos pelo trabalho de parto natural e também traria maiores benefícios para ela e para seu bebê. Muitas vezes a falta de informações da parturiente sobre o trabalho de parto não contribui no desempenho da assistência à puérpera. $\mathrm{O}$ desconhecimento do próprio corpo e do processo fisiológico da gestação geram sentimentos de dúvidas e incertezas e acabam levando a mulher à insegurança. As informações recebidas em seu contexto social e familiar também podem contribuir para que a parturiente não colabore e não tenha confiança no momento do parto. A dimensão sociocultural é capaz de interferir na afinidade que a mulher terá por certo tipo de parto, contribuindo para a formação de mitos, crenças e opiniões que reverberam na experiência singular de cada gestação ${ }^{15}$. Desta forma, a realização de ações educativas pelo enfermeiro obstetra durante o pré-natal torna-se relevante, gerando autoconfiança e reduzindo medo e angústias que a mulher apresenta no momento e da escolha do tipo de parto.

Exemplo é o que diz respeito ao uso excessivo da cesariana nas últimas três décadas. Foram fatores determinantes como o maior pagamento dos honorários profissionais para a cesárea, a economia de tempo e a realização clandestina da laqueadura tubária no momento do parto. Após anos desta prática, instituiu-se uma cultura pró-cesárea na população em geral e entre os médicos. Como consequência, muitos obstetras não se encontram motivados, e até mesmo capacitados, para o acompanhamento ao parto normal. Por sua vez, em uma relação médico-paciente assimétrica, as mulheres têm dificuldade em participar da decisão do tipo de parto, sentindo-se menos capacitadas para escolher e fazer valer seus desejos frente às "questões técnicas" levantadas pelos médicos ${ }^{16}$.

Vale destacar que o parto vaginal tem ocorrido de maneira oposta à sua normalidade e naturalidade, com muitas intervenções sendo realizadas. Para a realização do parto de forma tradicional, são utilizados, de maneira rotineira, alguns procedimentos como o corte na vagina, a colocação de soro na veia, a raspagem dos pelos, a lavagem intestinal, a suspensão da alimentação, o repouso na 
cama hospitalar, a proibição da presença de um acompanhante, dentre outras ações, que só causam sofrimento, dor e aumento do risco de inúmeras complicações à mãe e ao bebê, esclarecendo porque as mulheres têm medo do parto vaginal ${ }^{17}$.

\section{Categoria 6 - Falta de comprometimento/ envolvimento da equipe}

Esta categoria também ilustra falas que mostram interferências na questão do atendimento humanizado. A equipe de saúde deve estar empenhada a atender adequadamente todas as carências que acompanham as gestantes neste período, podendo ser fisiológicas, psicológicas ou educacionais $^{16}$. Para que isto aconteça, a equipe deve ser complacente com a dor da mulher e deve estar preparada, disposta e comprometida à implementação das ações assistenciais que amenizam essas carências.

"Acho que há falta de comprometimento e envolvimento da equipe." (E 03)

“Existem profissionais sem capacitação e sensibilização, equipe sem entrosamento.” (E 04)

"Percebe-se a presença de outros profissionais que não acreditam em parto humanizado" (E 05)

O processo de humanização do nascimento, que inclui também a possibilidade de um acompanhante à parturiente, envolve necessariamente uma mudança de atitudes ${ }^{18}$. Inicialmente do profissional de saúde, que é parte integrante da equipe que presta atenção integral a esta mulher, revendo seus conceitos, deixando de lado seus preconceitos, para favorecer um acolhimento completo e humano à mulher ${ }^{19}$. Envolve também a mudança de atitude da instituição, que deve estar estruturada e preparada para esta nova postura, incentivando, favorecendo, estimulando, treinando e controlando seus profissionais para o desempenho destas tarefas.

Conforme descrito pelas profissionais enfermeiras entrevistadas neste estudo, a falta de comprometimento, capacitação, sensibilização e envolvimento da equipe multidisciplinar vinculada no trabalho de parto atrapalham a realização das ações humanizadas desempenhadas por elas, levando em consideração que a enfermeira é o principal veículo de informação para implementação cultural, pela minimização do parto cesariano. É importante que o restante da equipe apoie e esteja inteiramente empenhado neste processo $^{5}$.

\section{Categoria 7 - Positiva/ Agradecimento/ Sorriso no rosto}

As entrevistadas relatam sobre a avaliação das parturientes durante a assistência recebida no parto natural. A avaliação das gestantes sobre a assistência prestada a elas neste momento de muita dificuldade e alegria é de suma importância para nortear as ações a serem prestadas às próximas gestantes que irão realizar seu parto na unidade ${ }^{8}$. Observando os fatores associados à satisfação ou 
a insatisfação para aperfeiçoá-los, o contentamento está vinculado à valorização das emoções e sentimentos da parturiente, estabelecendo uma relação de confiança e respeito aos anseios e angústias da gestante como também atendendo as suas necessidades e expectativas. A comunicação do enfermeiro com a mulher em seu ciclo gravídico-puerperal determina a satisfação na assistência ao parto. No entanto, falhas como a falta de diálogo interferem na qualidade assistencial, não permitindo a mulher expor suas dúvidas e com isso, gerando descontentamento. No entanto, existe a dificuldade para avaliação no momento da assistência perinatal, pois as mulheres tendem a se sentir aliviadas e agradecidas após o nascimento de uma criança saudável, compensando alguma experiência negativa durante a assistência.

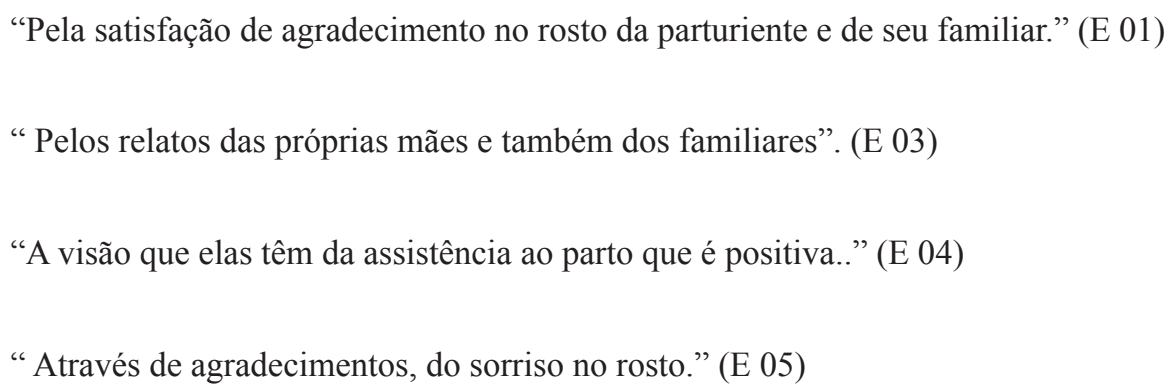

Diante dos relatos das entrevistadas, as avaliações das parturientes que receberam cuidados humanizadas durante do trabalho de parto foram positivas e de agradecimento. Essas reações norteiam o cuidado que estão sendo prestados, e as levam a continuar neste caminho. $\mathrm{O}$ atendimento humanizado é exatamente colocar seu conhecimento a serviço do bem-estar da mulher e do bebê, reconhecendo os momentos críticos em que suas intervenções são: minimizar a dor, ficar ao lado, dar conforto, esclarecer, orientar, além de ajudar a parir e a nascer. E, consequentemente, após realizar essas ações, recebem agradecimento das puérperas que normalmente não estão acostumadas com este tipo de tratamento ${ }^{20}$.

O alívio total da dor não necessariamente implica em uma experiência de parto mais satisfatório. No entanto, se a mulher sentir-se cuidada e confortada esta experiência poderá ser menos traumática, até porque, atualmente, as mulheres não temem apenas a dor no parto, elas sentem medo em relação aos cuidados que receberão, uma vez que as experiências estão repletas de atendimento impessoal e distante ${ }^{18}$.

\section{CONCLUSÕES}

Os resultados obtidos neste estudo revelaram que o parto humanizado sofre interferências quando se trata das ações cuidadoras que são implementadas durante o pré, intra e pós parto. No entanto a assistência prestada ao parto humanizado teve avaliação positiva das parturientes. Constatou-se que as ações cuidadoras implementadas durante o parto natural pelas enfermeiras foram as categorias: conversa terapêutica/orientação e a presença do profissional. Ao serem questionadas sobre a humanização na assistência ao parto, as entrevistadas citaram o apoio emocional e a assistência individualizada. Dentre as ações realizadas na assistência ao parto 
natural para torná-lo humanizado foram citados exercícios que facilitam o trabalho de parto e a presença do acompanhante. Dos fatores que interferem na humanização da assistência foi citado falta de envolvimento/ sensibilização da equipe e falta de cooperação da parturiente. Os enfermeiros relataram uma avaliação positiva dada pelas parturientes com relação à assistência prestada. Entendem-se então que o processo de parturição demanda, além de um conhecimento prático, teórico e científico, uma assistência digna e de qualidade que não seja limitada apenas a expulsão do feto do ventre materno. Por isso toda a equipe multidisciplinar envolvida na gestação, no trabalho de parto e no parto deve estar com o mesmo ideal de parturição natural humanista que atente aos sentimentos e valores da mulher, respeitando e apoiando suas vontades e direitos neste momento de fragilidade e alegria. O enfermeiro como cuidador direto tem grandes desafios para a implementação desta visão holística por parte da equipe multidisciplinar envolvida neste momento importante na vida da mulher.

\section{REFERÊNCIAS BIBLIOGRÁFICAS}

1. Moura FMSSP, Crizostomo CD, Nery IS, Medonça RCM, Araújo OD, Rocha SS. Humanization and nursing assistance to normal childbirth. Rev. bras. enferm. 2007; 60(4):452455

2. Brasil.Secretaria de Políticas de Saúde. Parto, aborto e puerpério: assistência humanizada a mulher. Brasília: Ministério da Saúde, 2001. Disponível em http://bvsms.saude.gov.br/bvs/ publicacoes/cd04_13.pdf.Acesso em 23/04/2012.

3. Rodrigues, DP, Silva RM, Fernandes AFC. Ação interativa enfermeiro-cliente na assistência obstétrica. R Enferm UERJ.2006;14(2):232-8.

4. Souza TG, Gaíva MAM, Modes PSSA. A humanização do nascimento: percepção dos profissionais de saúde que atuam na atenção ao parto. Rev Gaúcha Enferm. Rev. Gaúcha Enferm. 2011; 32(3): 479-86

5. Marques FC, Dias IMV, Azevedo L. A Percepção da equipe de Enfermagem sobre Humanização do Parto e Nascimento. Esc Anna Nery R Enferm. 2006; 10 (3): 439- 47.

6. Mouta RJO, Pilotto DTS, Vargens OMC et al.. Relação entre posição adotada pela mulher no, parto, integridade perineal e vitalidade do recém nascido. Rev. enferm. UERJ. 2008; $16(4): 472-6$.

7. Minayo MCS. O desafio do conhecimento:pesquisa qualitativa em saúde. 11. ed. São Paulo: Hucitec; Rio de Janeiro: Abrasco, 2008. 
8. Velho MB, Oliveira ME, Santos EKA. Reflexões sobre a assistência de enfermagem prestada à parturiente. Rev Bras Enferm. 2010; 63(4): 652-9 .

9. Mabuchi AS, Fustinoni SM. O significado dado pelo profissional de sa de para trabalho de parto e parto humanizado. Acta Paul Enferm 2008;21(3):420-6.

10. Longo CSM, Andraus LMS, Barbosa MA. Participação do acompanhante na humanização do parto e sua relação com a equipe de saúde. Revista Eletrônica de Enfermagem, 2010; Disponível em http://www.revistas.ufg.br/index.php/fen/article/view/5266/6945. Acesso em 20/08/2015.

11. Gomes ML. Enfermagem obstétrica: diretrizes assistenciais. Rio de Janeiro: Centro de Estudos da Faculdade de Enfermagem da Universidade do Estado do Rio de Janeiro, 2010; Disponível em http://abenfo.redesindical.com.br/arqs/manuais/027.pdf. Acesso em 23/04/2015.

12. Sescato AC, Kissula SRRS, Loewen Wall M. Os cuidados não-farcológicos para alívio da dor no trabalho de parto: orientações da equipe de enfermagem. Cogitare Enferm. 2008; 13(4):585-90

13. Oliveira ASS, Rodrigues DP, Guedes MVC, Felipe GF. Percepção de mulheres sobre a vivencia do trabalho de parto e parto. Rev. René. 2010; 11(esp): p. 32-41.

14. Machado NXS, Praça NS. Centro de parto normal e assistência obstétrica centrada nas necessidades da parturiente.Sãopaulo, 2004. Disponível em: http://www.scielo.br/pdf/reeusp/ v40n2/16.pdf. Acesso em 18/07/2015.

15. Albuquerque LC, Pereira EE, Rios CTF et al. Conhecimento de mulheres sobre o motivo para a realização do parto cesáreo. Revista do Hospital Universitário/UFMA.2007; 8(2): 9-16.

16. Diniz S, Chachan AS. O "corte por cima" e o "corte por baixo": o abuso de cesáreas e episiotomias em São Paulo. Questões de Saúde Reprodutiva. Questões de Saúde Reprodutiva.2006;I(1):80-91.

17. Carraro TE, Knobel R, Radunz V et al. Cuidado e conforto durante o trabalho de parto e parto: na busca pela opinião das mulheres. Texto Contexto Enferm, Florianópolis, 2006; 15 (Esp): 97-104.

18. Brüggemann OM, Parpinelli DM, Osis MJD. Apoio à parturiente por acompanhante de sua escolha em maternidade brasileira: ensaio clínico controlado randomizado. Rev Tempus Actas Saúde Col.2010;4(4):155-159. 
19. Silva RC ,Soares MC, Muniz RM et al. A Concepção dos profissionais de saúde sobre o parto humanizado na adolescência. Enfermería Global. 2011; 24:342-351.

20. Monte NL, Gomes JS, Amorin MA. A percepção das puérperas quanto ao parto humanizado em uma maternidade pública de Teresina-PI. Revista Interdisciplinar NOVAFAPI. 2011;4(3): 20-24.k

Artigo apresentado em 27/09/15 Artigo aprovado em 09/09/16 Artigo publicado no sistema em 05/10/16 